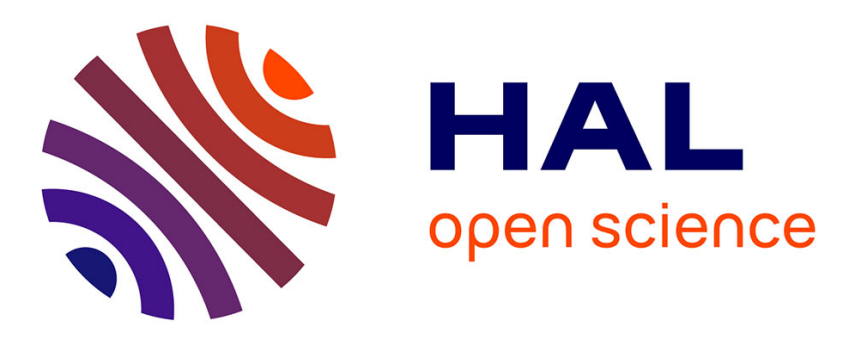

\title{
Understanding the evolution of the geometry of silicon solar cells
}

\author{
Philippe Arguel, Inès Massiot
}

\section{To cite this version:}

Philippe Arguel, Inès Massiot. Understanding the evolution of the geometry of silicon solar cells. Physics Education, 2020, 55 (1), pp.015006. 10.1088/1361-6552/ab4dda . hal-02348193

\section{HAL Id: hal-02348193 \\ https://hal.laas.fr/hal-02348193}

Submitted on 2 Dec 2020

HAL is a multi-disciplinary open access archive for the deposit and dissemination of scientific research documents, whether they are published or not. The documents may come from teaching and research institutions in France or abroad, or from public or private research centers.
L'archive ouverte pluridisciplinaire HAL, est destinée au dépôt et à la diffusion de documents scientifiques de niveau recherche, publiés ou non, émanant des établissements d'enseignement et de recherche français ou étrangers, des laboratoires publics ou privés. 


\title{
Understanding the evolution of the geometry of silicon solar cells
}

\author{
P Arguel \& I Massiot \\ Laboratory of Analysis and Architecture of Systems (LAAS-CNRS), Université \\ Toulouse, CNRS, UPS, 7 avenue du Colonel Roche, 31031 Toulouse, France \\ E-mail: ines.massiot@laas.fr
}

\begin{abstract}
Today, solar cells are very familiar to the broad public, and everyone has noticed their particular geometry resembling a square with rounded-off corners. However, the rationale behind this geometry is little known. This paper presents a precise study of the geometry of silicon solar cells and its evolution since their appearance in the early 1960s. Through a parametric approach taking into account different types of constraints, it is shown that the cell geometry is the result of an optimization process depending on both technical and economic aspects. The correlation between the parametric study and historical data shows that the photovoltaic panels that we see today on our roofs have been mainly shaped by the evolution of cost constraints over the past decades.
\end{abstract}

Keywords: Silicon solar cells, Solar cell geometry, Photovoltaics engineering 


\section{Introduction}

The development of photovoltaic energy started at the end of the 1950s, motivated in particular by the crucial issue of powering up the first satellites [1]. A similar motivation arose for terrestrial applications in isolated areas opening up new prospects for research on solar cells at the beginning of the 1960s [2]. Most studies were focused on photovoltaic devices made of monocrystalline silicon leading to the best conversion efficiency at the time [3]. Later, the growth of photovoltaics and its various applications has relied on multiple technologies using different materials such as polycrystalline silicon, organic polymers or multijunction structures based on III-V semiconductors. Nevertheless, despite the diversity of architectures and materials, monocrystalline silicon remains currently the technology used in the fabrication of a third of commercial solar cells [4].

Solar cells are now very familiar to the broad public, as photovoltaic panels have started to cover more and more buildings. Everyone has noticed their particular geometry resembling, at first sight, a square with rounded-off corners as illustrated in figure 1(a). However, this is far from the original geometry of the disk directly obtained from the sawing of a cylindrical ingot of silicon in identical circular slices called wafers.

In this article, the evolution of the geometry of silicon solar cells is studied from its origins to the present day. It is shown that the current geometry results from an optimization process based on several parameters that are identified and described. The general framework of the study is the design of conventional photovoltaic panels (or modules) made of bidimensional arrays of identical elements, that are also called components, each containing one solar cell. Figure 1 illustrates such arrays based on circular (figure 1(b)) and square (figure 1(c)) cells. For the sake of simplicity, the process of optimizing the geometry of solar cells is carried out on a single component of the photovoltaic module. The photovoltaic module being an array of identical elements, the results of the optimization performed to design one component can then be extended to the whole module.

\section{Description of the model to study the solar cell geometry}

\subsection{Definition of the optimization parameters}

A single element of the module is defined as a square component with a side length $L$, enclosing a solar cell fabricated from a wafer of diameter $D$ (figure 2(a)). The sides of the solar cell of surface area $A$ are always considered to be tangent to the sides of the square component of surface area $A^{\prime}=L^{2}$. A third useful parameter for this study is the length of the chord $C$ as illustrated in figure $2(\mathrm{a})$.

Two extreme cases can then be distinguished: (i) the cell is directly made from the circular wafer (figure 2(b)) and (ii) the circular wafer is sawed to make a square cell of maximal area (figure $2(\mathrm{c})$ ).

In the first case (circular cell with a diameter $D$ ), the side length of the component is equal to $L=D$ and thus $C=0$. The cell area is then given by $A=A_{\text {cir }}=\pi D^{2} / 4$. 


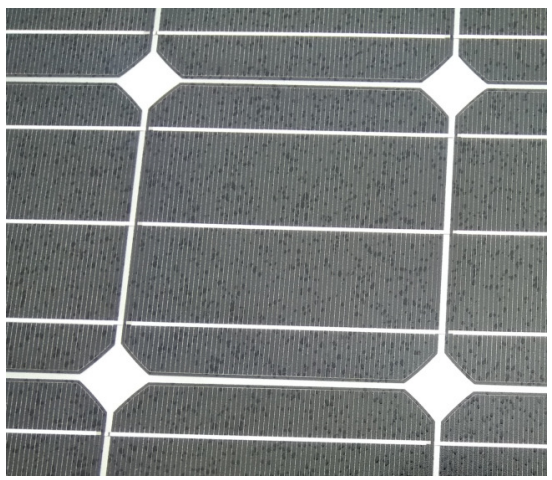

(a)

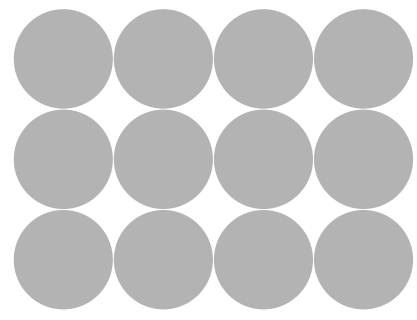

(b)

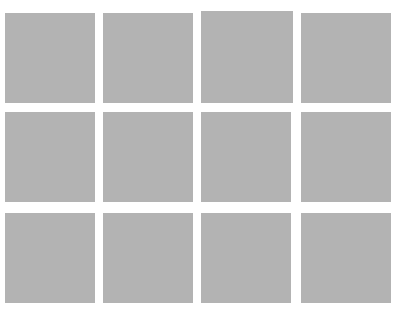

(c)

Figure 1. (a) Photograph of a monocrystalline silicon solar cell. (b,c) Schematics of a photovoltaic module based on a 3x4 array made with (b) circular and (c) square cells.

In case (ii), the cell and the component overlap, leading to $L=D / \sqrt{2}=C$. The cell area can then be expressed as $A=A_{\text {squ }}=D^{2} / 2$.

In between those two cases, the cell is a regular truncated disk with an area $A$ such as $D^{2} / 2 \leq A \leq \pi D^{2} / 4$. In order to characterize such a cell with respect to cases (i) and (ii), two parameters can be defined as follows:

- the usage rate of the silicon wafer $U_{w}$ that can be expressed as

$$
U_{w}=\frac{A}{A_{\text {circ }}}=\frac{4 A}{\pi D^{2}}
$$

- the surface coverage of the component $C_{c}$ that can be expressed as

$$
C_{c}=\frac{A}{A^{\prime}}=\frac{A}{L^{2}} \text {. }
$$

The case (i) of circular cells corresponds to $A=A_{c i r}$, leading to $U_{w}=1$ and $C_{c}=\pi / 4 \approx 0.79$. Likewise, in the case (ii) of square cells with maximal area, $C_{c}=1$ and $U_{w}=2 / \pi \approx 0.64$. The parameters $U_{w}$ and $C_{c}$ thus vary inversely with respect to each other when the geometry of the solar cell goes from a circular wafer to a perfect square, or conversely.

Designing the optimal geometry of the solar cell (and thus the module itself) requires to take into account a whole set of factors (material cost, fabrication cost, module footprint, power conversion efficiency, final cost of $\mathrm{kWh}$, module weight, etc). The importance of these factors in the module design depends on the market module price and the application aimed for the module. For instance, the design process has to 


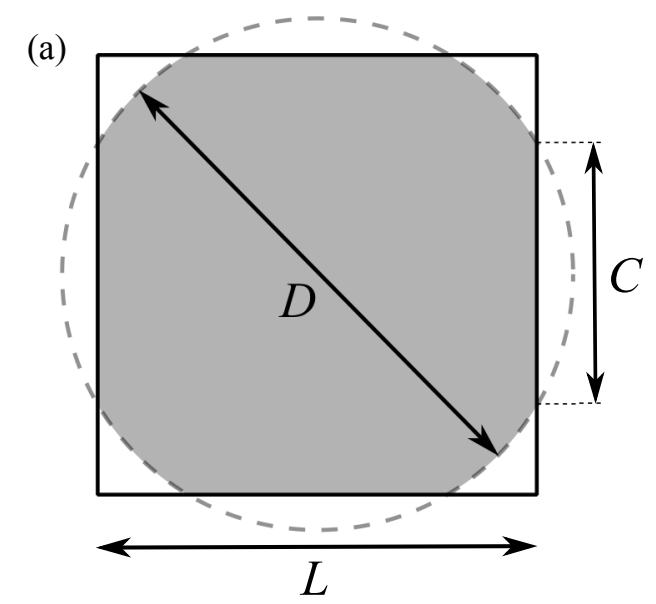

(b)

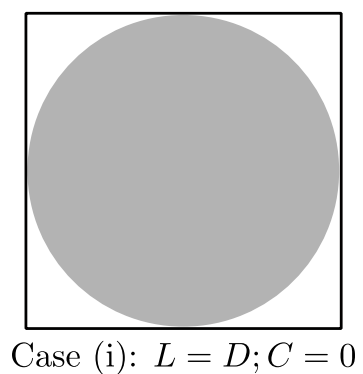

(c)

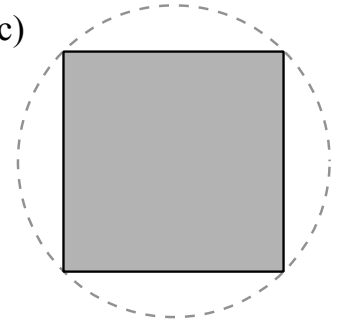

Case (ii): $L=D / \sqrt{2}=C$

Figure 2. Geometrical parameters of the model. (a) Schematics of a single square component of the module (side length $L$ ). The outline of the initial circular wafer of diameter $D$ is shown with dashed lines. The grey area represents the area effectively covered by the cell, corresponding to a regular truncated disk of chord $C$. (b) Illustration of the case (i) where the cell is made of a circular wafer without sawing. (c) Illustration of the case (ii) where the circular wafer is sawed into a square cell of maximal area.

adapt to the specifications of building-integrated photovoltaics or embedded systems. As an example, the case $C_{c}=1$ (square cells) could correspond to a module design combining a high conversion efficiency with a low footprint as sought after in the aerospace or space industry. On the other hand, for domestic photovoltaic applications where the solar panels are placed on a roof or a large terrace, the footprint is less restrictive and sawing a large part of the wafers can then be avoided. In this case, the $U_{w}$ parameter can get closer to 1 (circular cells).

The specifications dictated by the targeted application should be taken into account in the model for the geometrical design of the cell. To do so, a weighting coefficient $\gamma$ can be defined to indicate the relative importance of $U_{w}$ with respect to $C_{c}$ :

$$
\gamma=\frac{U_{w}}{C_{c}}
$$

Inserting the expressions for $U_{w}$ and $C_{c}$ given by (1) and (2) into (3) leads to the following relation between $\gamma, L$ and $D$ :

$$
\gamma=\frac{4}{\pi}\left(\frac{L}{D}\right)^{2} \text {. }
$$


By definition, the range of values that $\gamma$ can take is bounded by cases (i) and (ii):

$$
\frac{D}{\sqrt{2}} \leq L \leq D \Longrightarrow \frac{2}{\pi} \leq \gamma \leq \frac{4}{\pi}
$$

The following study is thus restrained to $\gamma \in[2 / \pi ; 4 / \pi]$.

\subsection{Expression of the solar cell area}

Let us consider a solar cell as defined in figure 2(a). Its area $A$ can be obtained from the initial area of the wafer $A_{\text {cir }}$ and the area $A_{s}$ of each of the four circular segments that have been sawed (depicted in shaded areas in figure 3):

$$
A=A_{\text {cir }}-4 A_{s} \text {. }
$$

Such a circular segment can be described as the region of the wafer bounded by an arc of angle $2 \theta$ and by the chord of length $C$. The area $A_{s}$ can then be expressed as a function of $A_{\text {sec }}$ the area of the circular sector of angle $2 \theta$ and $A_{t r i}$ the area of the triangular portion:

$$
A_{s}=A_{\text {sec }}-A_{\text {tri }} .
$$

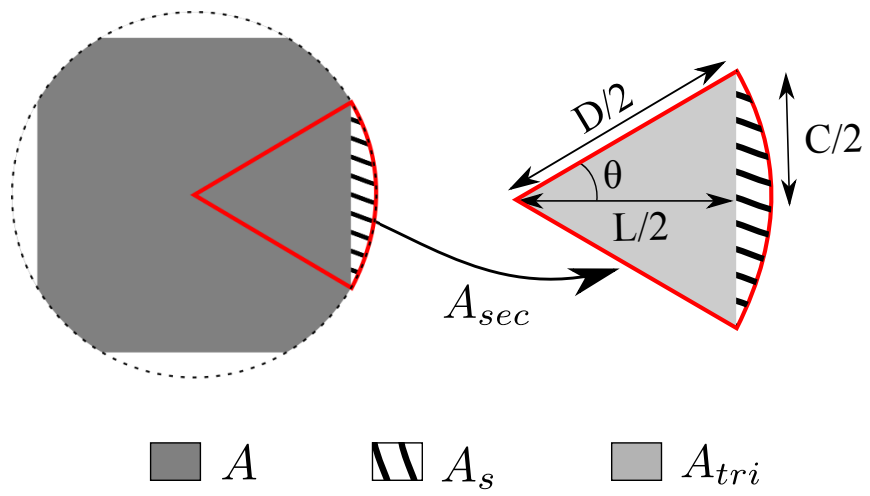

Figure 3. Illustration of the different areas used in the calculation of the solar cell area $A$ (dark grey area): the area $A_{s}$ of each of the four circular segments (dashed area), the area $A_{\text {sec }}$ of the circular sector of angle $2 \theta$ (area surrounded in a thick line) and $A_{t r i}$ the area of the triangular portion (light grey area).

As $\cos (\theta)=L / D$, the area of the circular sector is given by:

$$
A_{\text {sec }}=\frac{\theta}{\pi} A_{\text {cir }}=\frac{D^{2}}{4} \cos ^{-1}\left(\frac{L}{D}\right) .
$$

Furthermore, using $D^{2}=L^{2}+C^{2}, A_{t r i}$ can be expressed as:

$$
A_{t r i}=\frac{C L}{4}=\frac{L}{4} \sqrt{D^{2}-L^{2}} .
$$

The expression for $A_{s}$ can then be obtained by combining (7), (8) and (9):

$$
A_{s}=\frac{1}{4}\left[D^{2} \cos ^{-1}\left(\frac{L}{D}\right)-L \sqrt{D^{2}-L^{2}}\right] \text {. }
$$


Inserting (10) in (6) then gives an expression for $A$ as a function of $L$ and $D$ :

$$
A=\frac{\pi D^{2}}{4}-D^{2} \cos ^{-1}\left(\frac{L}{D}\right)+L \sqrt{D^{2}-L^{2}} .
$$

The area $A$ can subsequently be expressed as a function of the weighting coefficient $\gamma$ by inserting (4) in (11):

$$
A=\frac{\pi D^{2}}{4}\left[1-\frac{4}{\pi} \cos ^{-1}\left(\sqrt{\frac{\gamma \pi}{4}}\right)+\frac{2}{\pi}\left[\gamma \pi\left(1-\frac{\gamma \pi}{4}\right)\right]^{1 / 2}\right] .
$$

Finally, the parameters $U_{w}$ and $C_{c}$ can be obtained using (1) and (3):

$$
\begin{aligned}
& U_{w}=1-\frac{4}{\pi} \cos ^{-1}\left(\sqrt{\frac{\gamma \pi}{4}}\right)+\frac{2}{\pi}\left[\gamma \pi\left(1-\frac{\gamma \pi}{4}\right)\right]^{1 / 2} . \\
& C_{c}=\frac{1}{\gamma}\left[1-\frac{4}{\pi} \cos ^{-1}\left(\sqrt{\frac{\gamma \pi}{4}}\right)+\frac{2}{\pi}\left[\gamma \pi\left(1-\frac{\gamma \pi}{4}\right)\right]^{1 / 2}\right] .
\end{aligned}
$$

\section{Results}

Let us consider a silicon wafer with a given diameter value $D$. Figure 4(a) presents the variation of $U_{w}$ and $C_{c}$ as a function of the weighting coefficient $\gamma(2 / \pi \leq \gamma \leq 4 / \pi)$. As expected, the two parameters vary inversely with respect to each other when $\gamma$ changes. Given the specifications of a targeted application for the solar module, the first step is to define a value for $\gamma$. Once the value of $\gamma$ is known, the optimal values for $U_{w}$ and $C_{c}$ can be found using figure 4(a), thus leading to the best geometry for the solar cell.

Here, since the optimization process is carried out without specific constraints, the optimal value of $\gamma$ is searched by maximizing the product $U_{w} * C_{c}$. According to figure 4(b) which displays the variation of $U_{w} * C_{c}$ as a function of $\gamma$, the optimal value is $\gamma=\gamma_{0} \approx 1.065$. Using (12), the corresponding cell area is determined as:

$$
A=A_{0} \approx 0.94\left(\frac{\pi D^{2}}{4}\right) .
$$

Likewise, the optimal values of the usage rate of the wafer $U_{w}$ and the surface coverage of the component $C_{c}$ can be obtained from (13) and (14) giving: $U_{w_{0}} \approx 0.94$ and $C_{c_{0}} \approx 0.88$.

In practice, for manufacturing a photovoltaic module made of silicon wafers, the three parameters that are commonly used to define the geometry of the solar cell are $D$ (diameter), $L$ (full side length) and $C$ (length of the chord). Figure 5 shows the variation of the normalized parameters $L / D$ and $C / D$ as a function of the coefficient $\gamma$. Table 1 gathers several values of $L / D, C / D$ and the corresponding values of $U_{w}$ and $C_{c}$.

In the case where $\gamma=\gamma_{0}$, the corresponding optimal side length of the square component of the module can be calculated as a function of the wafer diameter $D$ using (4), leading to: $L=L_{0} \approx 0.915 D$. As for the length of the chord of angle $2 \theta$, it can be determined using the following expression:

$$
C=\sqrt{D^{2}-L^{2}}=D\left[1-\left(\frac{L}{D}\right)^{2}\right]^{1 / 2}=D\left[1-\frac{\gamma \pi}{4}\right]^{1 / 2} .
$$



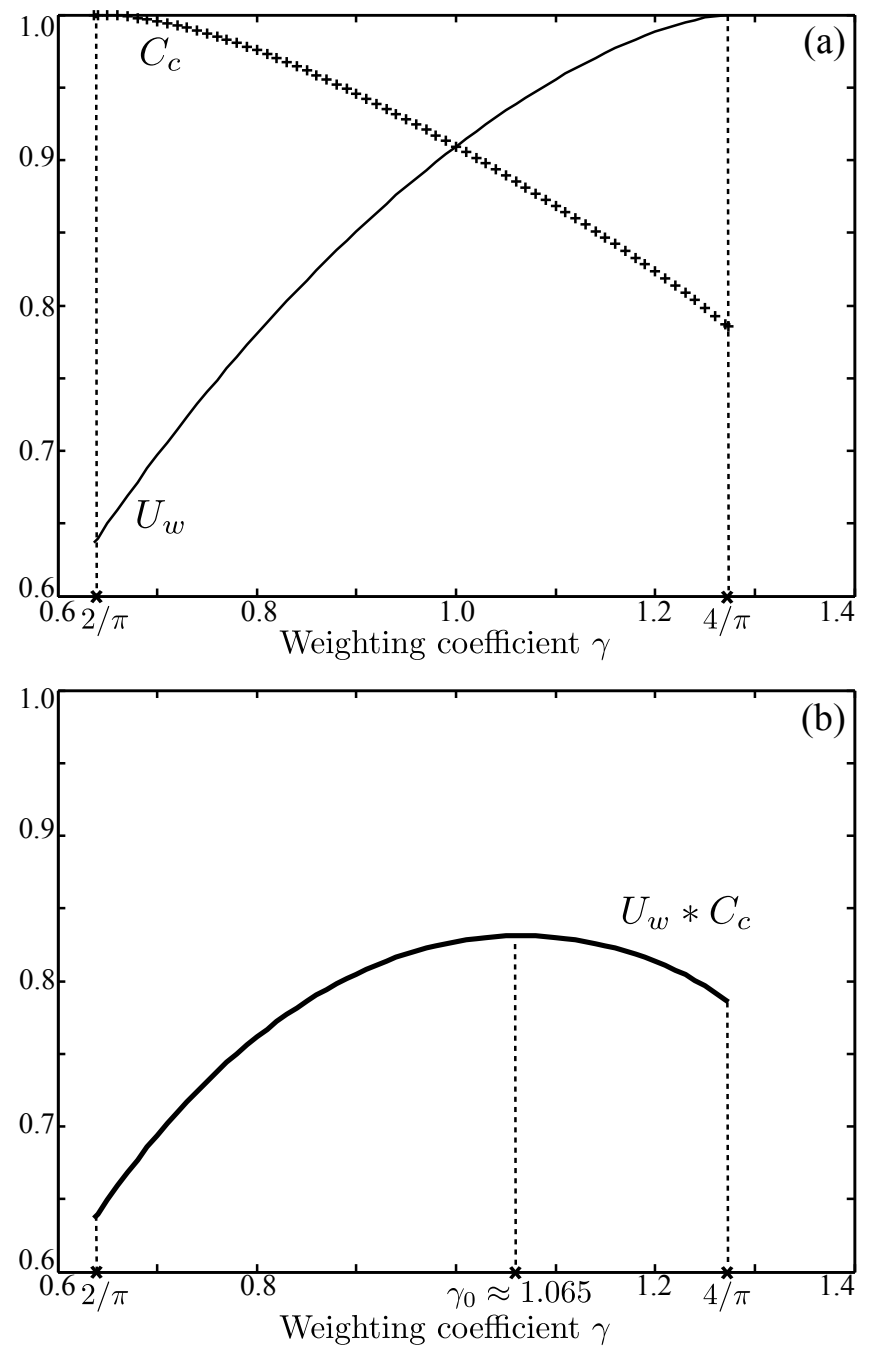

Figure 4. Variation of (a) $U_{w}$ and $C_{c}$ and (b) $U_{w} * C_{c}$ as a function of the weighting coefficient $\gamma(\gamma \in[2 / \pi ; 4 / \pi])$. The value $\gamma=\gamma_{0} \approx 1.065$ corresponding to the maximum of $U_{w} * C_{c}$ is highlighted.

Table 1. Values of the geometrical parameters of the solar cell for notable values of the weighting coefficient $\gamma$.

\begin{tabular}{ccccc}
\hline$\gamma$ & $L / D$ & $C / D$ & $U_{w}(\%)$ & $C_{c}(\%)$ \\
\hline $2 / \pi$ & $\mathbf{0 . 7 0 7}$ & $\mathbf{0 . 7 0 7}$ & $\mathbf{6 3 . 7}$ & $\mathbf{1 0 0}$ \\
0.7 & 0.741 & 0.671 & 69.7 & 99.6 \\
0.8 & 0.793 & 0.610 & 78.0 & 97.6 \\
0.9 & 0.841 & 0.541 & 85.1 & 94.6 \\
1 & 0.886 & 0.463 & 90.9 & 90.9 \\
$\gamma_{0} \approx 1.065$ & $\mathbf{0 . 9 1 5}$ & $\mathbf{0 . 4 0 3}$ & $\mathbf{9 4 . 1}$ & $\mathbf{8 8 . 3}$ \\
1.1 & 0.929 & 0.369 & 95.6 & 86.9 \\
1.2 & 0.971 & 0.240 & 98.8 & 82.3 \\
$4 / \pi$ & $\mathbf{1}$ & $\mathbf{0}$ & $\mathbf{1 0 0}$ & $\mathbf{7 8 . 5}$ \\
\hline
\end{tabular}




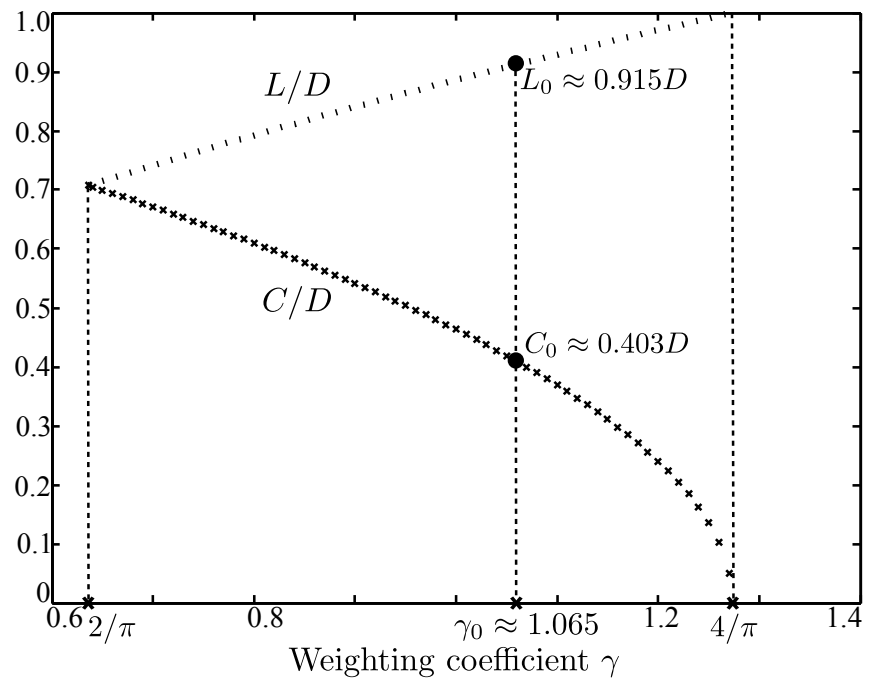

Figure 5. Variation of $L / D$ and $C / D$ as a function of the weighting coefficient $\gamma$ $(2 / \pi \leq \gamma \leq 4 / \pi)$. The values of the side length $L_{0}$ and the chord length $C_{0}$ as a function of $\mathrm{D}$ corresponding to $\gamma=\gamma_{0}$ are highlighted.

The optimal value of $C$ is then: $C=C_{0} \approx 0.403 D$. Figure 6 shows the optimal geometry of the solar cell designed using $L_{0}$ and $C_{0}$ (figure $6(\mathrm{a})$ ) and a module made of $3 \times 3$ cells with such a geometry (figure 6(b)).

Beyond the previous case where $\gamma=\gamma_{0}$, figure 7 illustrates the evolution of the optimal geometry of the solar cell when the coefficient $\gamma$ varies from $4 / \pi$ to $2 / \pi$.

\section{Discussion}

In the 1960s and 1970s, the first solar panels made for terrestrial applications consisted of circular solar cells [5]. The value of the weighting coefficient $\gamma$ was then equal to $4 / \pi$. As mentioned earlier, current silicon solar cells have the geometry of a square with rounded-off corners (see figure 1(a)). In order to shed some light on this evolution of the solar cell geometry, technical data of solar cells over the last six decades were gathered using a review paper [5] and commercial datasheets $[6,7,8,9,10,11,12]$. For each solar cell, the values of the weighting coefficient $\gamma$ and the diameter $D$ were extracted. As a result, figure 8(a) shows the evolution of these two parameters ( $\gamma$ in full circles and $D$ in open triangles) over time. In addition, figure 8(b) illustrates the evolution of the geometry with some examples of solar cells and the values of the corresponding geometrical parameters are given in table 2.

In order to illustrate the evolution of the solar module price over time, the standard metrics used is the cost per watt-peak expressed in $\$ / \mathrm{Wp}$. The Watt-peak is the unit used to express the electrical power generated by a photovoltaic module under standard test conditions, i.e. a solar irradiance of $1000 \mathrm{~W} / \mathrm{m}^{2}$ with an air mass 1.5 (AM1.5) spectrum under normal incidence, and a temperature of $25^{\circ} \mathrm{C}$. Figure 9 displays the evolution of the cost per watt-peak for crystalline silicon solar cells over the last five 


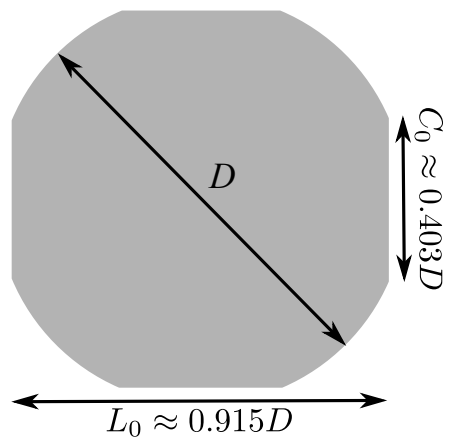

(a)

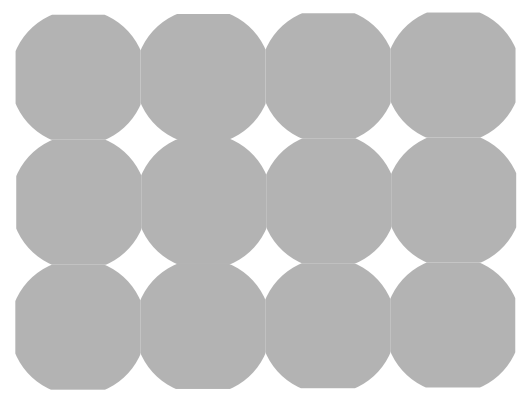

(b)

Figure 6. Optimal geometry of (a) a single cell and (b) a module of $3 \times 4$ cells, corresponding to $\gamma=\gamma_{0}$.

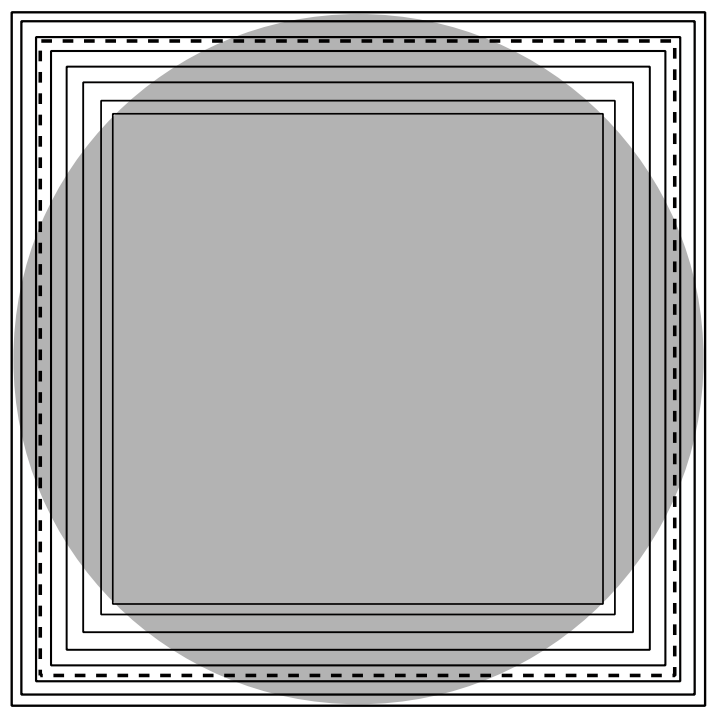

Figure 7. Illustration of the evolution of the optimal cell geometry as a function of $\gamma$ varying from $4 / \pi$ (circular cell) to $2 / \pi$ (square cell of maximal area). The component containing the cell is shown with a square for the following values of $\gamma$, from the outer edge to the center of the figure respectively: $4 / \pi ; 1.2 ; 1.1 ; \gamma=\gamma_{0} \approx 1.065$ (dashed lines); $1 ; 0.9 ; 0.8 ; 0.7 ; 2 / \pi$. The dark grey area represents the initial circular wafer. 
Table 2. Values of the geometrical parameters of the commercial solar cells depicted in figure 8(b).

\begin{tabular}{ccccc}
\hline Year & $D(\mathrm{~mm})$ & $L(\mathrm{~mm})$ & $\gamma$ & Reference \\
\hline 1960 & 20 & 20 & $4 / \pi$ & {$[5]$} \\
1975 & 57 & 57 & $4 / \pi$ & {$[5]$} \\
1998 & 113 & 103 & 1.05 & {$[6]$} \\
2002 & 127 & 108 & 0.92 & {$[7]$} \\
2010 & 160 & 125 & 0.78 & {$[8]$} \\
2018 & 210 & 157 & 0.7 & {$[12]$} \\
\hline
\end{tabular}

decades, using data taken from $[5,13,14,15,16]$. The values given are the costs for the solar cell alone corrected to 2019 US dollars.

Comparing figures 8 and 9 provides an insight on the impact of the cost of the solar cell on its geometry. In the 1960s-1970s, the geometry of solar cells for terrestrial applications remained circular due to the high cost of silicon wafer fabrication. However, while keeping a circular geometry, the evolution and the growing control of silicon microelectronic technologies have led to an increase of the cell diameter from $20 \mathrm{~mm}$ in 1960 to $57 \mathrm{~mm}$ in 1975 (see figure 8(b)). Thereafter, silicon wafers have kept on growing larger and their production has accelerated to respond to the increasing demand of the booming microelectronic industry. This growth of silicon production has led to a significant drop in the fabrication cost of wafers translating into a drastic decrease in the cost per watt-peak as illustrated in figure 9, with a fortyfold cost reduction from 1970 to 1990. Releasing the cost constraint has induced a decrease of the usage rate of the silicon wafer, and thereby of the coefficient $\gamma$ since the 1980s as can be clearly seen in figure 8a. Looking more closely at the evolution after 2000, one should note that the cost reduction is not monotonous as can be seen in the inset of figure 9. In particular, there was an increase of the cost per watt-peak in 2006 resulting from a shortage in the polysilicon material used to fabricate the monocrystalline silicon ingots [14]. The decrease in the cost slows down after 2010, with only a twofold cost reduction from 2010 to 2015. After 2015, the cost per watt-peak levels off around 0.4-0.8 $\$ / \mathrm{Wp}$ with slight variations following the silicon price. These low cost values translate into the fabrication of cells with $\gamma \approx 2 / \pi$ corresponding to a square or quasi-square geometry (see figures $8 \mathrm{a}$ and $8 \mathrm{~b})$.

Along history, the geometry of silicon solar cells has gradually evolved from the initial circular wafers to regular truncated disks and, today, to square or quasi-square cells. This parametric study suggests that this evolution of the solar cell geometry can be mainly attributed to the economic constraint weighting on the usage rate of the silicon wafers used for the cell fabrication. 

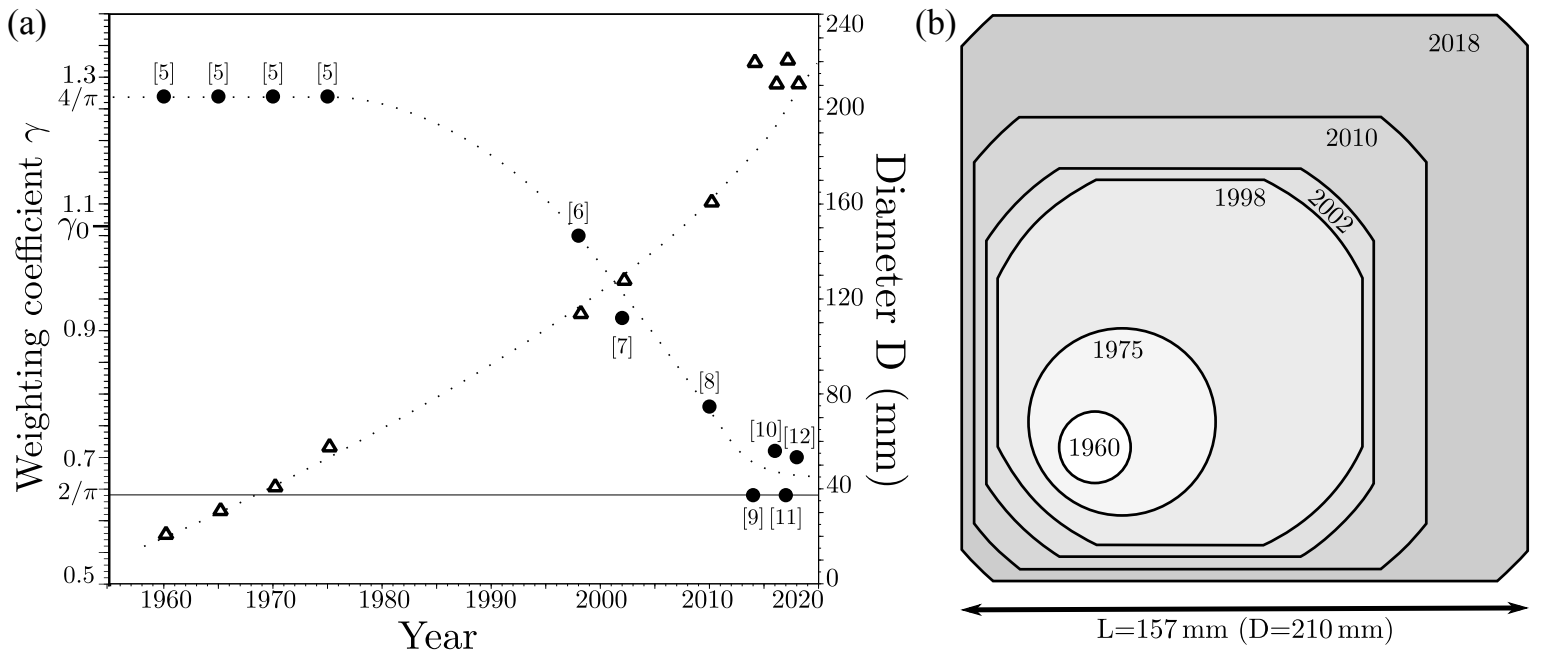

Figure 8. Historical evolution of the geometry of monocristalline silicon solar cells. (a) Evolution of the weighting coefficient $\gamma$ (full circles) and the cell diameter $D$ (open triangles). The dotted lines act as a guide for the reader's eye to highlight the evolution of the value of $\gamma$ from $4 / \pi$ in the 1960s-1970s to approximately $2 / \pi$ today. The horizontal thin line shows the $2 / \pi$ bound corresponding to square cells. (b) Comparison of some examples of solar cell geometries. The data used in both figures come from $[5,6,7,8,9,10,11,12]$.

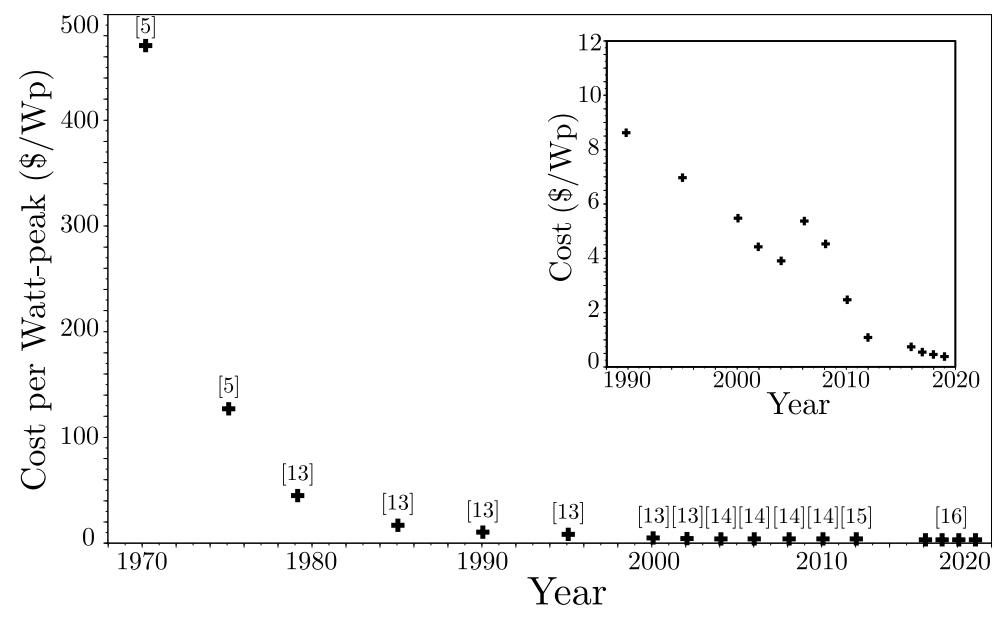

Figure 9. Historical evolution of the cost per watt-peak of crystalline silicon solar cells. Data prior to 1970 are not shown, they have little significance as the photovoltaic industry really started in the 1970s. The inset displays a zoom on the time range from 1990 to 2019. The data used in the figure come from [5, 13, 14, 15, 16]. All costs are corrected to 2019 US dollars.

\section{Conclusion}

The development of silicon solar cells for terrestrial applications began in the 1960s. Since that time, technologies have diversified and the geometry of monocrystalline silicon cells has gradually evolved from a disk to a square. This paper describes a simple parametric model to quantify the evolution of the solar cell geometry. The 
correlation with historical data suggests that the main parameter driving the solar cell geometry is the economic constraints weighting on solar cell fabrication. In the future, potential evolutions such as a drop in silicon market could add a new constraint and drive the optimization process towards another solar cell geometry. Interestingly, one can note that in the case of other technologies such as polycrystalline silicon or thin film materials relying on fabrication processes with a lower cost, the solar cells have kept a square geometry from the beginning.

\section{Acknowledgments}

The authors gratefully acknowledge Guy Vialaret (former engineer at LAAS-CNRS), Etienne Rapp (CNES) and Lionel Séguier (LAAS-CNRS) for their help in gathering historical data on photovoltaic panels and solar cells.

\section{References}

[1] Bailey S and Raffaelle R 2010 Solar Cells and Their Applications (John Wiley and Sons) part IV chap 18.

[2] Starr M R 1989 Applications of Photovoltaics (CRC Press) chap 1.

[3] Green M A 2012 Solar Cells: Materials, Manufacture and Operation (Newnes) p 87-110.

[4] Fraunhofer Institute for Solar Energy Systems 2019 Photovoltaics Report (url: www.ise. fraunhofer.de).

[5] Salles Y 1975 L'évolution industrielle des cellules solaires au silicium Acta Electronica 18 339-343.

[6] Siemens 1998, Data sheet of solar module SP75.

[7] BP Solar 2002, Data sheet of solar module BP 5170.

[8] SunPower 2010, Data sheet of solar cell C60.

[9] CSun Solar 2014, Data sheet of solar cell JAC M6SR-3.

[10] E-Ton 2016, Data sheet of solar cell ExcelTon II 4BB.

[11] Photowatt 2017, Data sheet of solar module PW2500F.

[12] Neo Solar Power 2018, Data sheet of solar cell NS6WL.

[13] Swanson R M 2006 A vision for crystalline silicon photovoltaics Prog. Photovolt: Res. Appl. 14 443-453.

[14] IRENA 2012 Solar Photovoltaics Renewable Energy technologies: cost analysis series p 15-16.

[15] Kavlak G 2018 Evaluating the causes of cost reduction in photovoltaic modules Energy Policy 123 700-710.

[16] PV Magazine 16 september 2019 Module price index (url: https://www.pv-magazine.com/ features/investors/module-price-index/). 